\title{
GEOGRAFIA E MÚSICA: A RELAÇÃO ENTRE A MIGRAÇÃo JAMAICANA E A MÚSICA INTERNACIONAL
}

\author{
João Pedro Turino ${ }^{1}$, Luciana Carolina Fernandes de Faria ${ }^{2}$ \\ 1 Universidade Estadual Paulista - UNESP, Licenciatura - Geografia, Presidente Prudente, SP. E-mail: \\ jp turino@hotmail.com, ${ }^{2}$ Universidade do Oeste Paulista - UNOESTE, Curso de Licenciatura em Música, Presidente \\ Prudente, SP.
}

\section{RESUMO}

Reconhecendo a música como meio de entender sociedades e povos, experimenta-se nesse artigo compreender a influência da cultura jamaicana no desenvolvimento músicas norte-americanos e ingleses. Por conta da emigração e forte presença nos guetos e periferias nas capitais internacionais da música, elementos vindos da música jamaicana podem ser notados até hoje nas músicas americanas e inglesas. Os ritmos tradicionais da Jamaica analisados foram o Mento, o Ska, o Reggae e o Dub. Com a análise de quatro canções torna-se evidente o impacto da cultura Jamaicana nas músicas internacionais, justificado pela imigração para essas nações protagonistas nas rádios e na cultura posta como "cool", apreende-se também que a resistência cultural, que por meio da música, das roupas e dos ideais denunciava e denuncia a realidade de um imigrante, a vida em guetos, as injustiças e contradições e deixa claro a música como refúgio, um momento para sentir-se vivo.

Palavras-chave: Música jamaicana, Geografia e música, International Music, Migração e Cultura.

\section{GEOGRAPHY AND MUSIC: A RELATIONSHIP BETWEEN A JAMAICAN MIGRATION AND THE INTERNATIONAL MUSIC}

\begin{abstract}
Recognizing music as a means of understanding societies and peoples, experienced in this article to understand the influence of the Jamaican culture in the development of American and English songs. Due to the emigration and strong presence in the ghettos and peripheries in the international capitals of music, elements coming from Jamaican music can be noticed in the American and English songs. The traditional rhythms of Jamaica analyzed were Mento, Ska, Reggae and Dub. With the analysis of four songs, the impact of Jamaican culture on international music is evident, justified by immigration to these leading nations in radios and in the culture posed as "cool", it is also perceived that cultural resistance, through music, clothes and ideals denounced and denounced the reality of an immigrant, life in ghettos, injustices and contradictions and makes music clear as a refuge, a moment to feel alive.Keywords: Jamaican Music, Geography and Music, International Music, Migration and Culture.
\end{abstract}




\section{INTRODUÇÃO}

Atualmente com uma população de quase três milhões de pessoas ${ }^{1}$, a Jamaica, ilha situada no Caribe, foi colonizada pelos espanhóis em 1494 e posteriormente pelos ingleses em 1655. A ilha era habitada por ameríndios pacíficos, até que em 1494, em uma expedição liderada por Colombo, os espanhóis colonizaram e passaram a ocupar a área. Os espanhóis usaram da mão obra escrava vinda da África para a produção de açúcar, sendo aplicada a "plantation", ou seja, grandes latifúndios, trabalho escravo e monocultura, no caso o açúcar.

Já em 1655, os ingleses invadiram a ilha e a dominaram, tornando-a parada importante para os navios que vinham da Europa em direção a América Central ou aos Estados Unidos, devido ser um domínio inglês. Esta situação de colônia fez da Jamaica um ponto de resistência inglês em meio a colônias em maioria espanholas. Desta forma, a língua oficial da Jamaica tornou-se o inglês.

A proximidade política da coroa britânica com a Jamaica e a localização geográfica da ilha proporcionou uma migração intensa para vários países próximos, dentre eles os Estados Unidos e a Inglaterra. A migração para os Estados Unidos se deu ao longo da história pós-escravidão (pós1883), chamada de segunda diáspora (RIBEIRO, 1994). Assim, os negros jamaicanos ocuparam cidades que ofereciam oportunidade emprego, não só nos Estados Unidos, mas também em outros países da América Latina. Já a migração para o Reino Unido se deu em maior intensidade entre os anos de 1945 e 1960, época pós-Segunda Guerra Mundial, período em que a coroa britânica buscava reconstruir o país e suas colônias proveram mão-de-obra para isso.

Os jamaicanos, em sua grande maioria, chegavam ao Reino Unido e aos Estados Unidos sem qualificação, ocupavam os cargos que exigiam força física e recebiam salários também menores que os dos nativos. Logo ocuparam os guetos e bairros mais periféricos como Bronx (Nova York) e Brixton (Londres). Ao compartilharem a realidade de periferia com outros moradores, a cultura jamaicana foi sendo disseminada neste espaço e, com o tempo, alguns de seus elementos influenciaram e passaram a integrar a cultura destes países dominantes também.

Desta mescla cultural, é possível notar na música o surgimento do Hip Hop e a difusão de estilos originalmente jamaicanos como o Reggae e o Ska. Com o desenvolvimento da indústria fonográfica e dos estilos musicais essencialmente norte americanos e ingleses, percebe-se que a música jamaicana influenciou em alguns aspectos musicais, de forma que alguns de seus elementos mais marcantes foram agregados às músicas inglesas e norte-americanas.

Para Raibaud (2008), as práticas musicais de cada povo são geo-indicadores da organização dos territórios, articulando com valores culturais, sociais e mesmo com o sentimento de pertencimento. Destarte, o objetivo deste artigo é analisar, a partir da influência dos imigrantes, o desenvolvimento das músicas americanas e britânicas e as características musicais que as aproximam da música jamaicana, sobretudo do Reggae, Ska, Mento e Dub.

\section{METODOLOGIA}

Para estabelecer paralelos e verificar se as músicas inglesas e norte-americanas apresentam influências da música jamaicana, foi realizada análise musical de quatro estilos originalmente jamaicanos (Reggae, Ska, Mento e Dub) e destacadas as suas principais características musicais. Posteriormente, a mesma análise foi feita com músicas norte-americanas e as inglesas, a fim de encontrar possíveis semelhanças em sua estrutura e linguagem musical, como está apresentado a seguir.

\section{RESULTADOS}

Para identificar os elementos marcantes na música jamaicana e poder traçar paralelos com as músicas inglesas e norte-americanas, foram analisados quatro estilos: Mento, Ska, Reggae e

${ }^{1}$ Cf. INDEXMUNDI http://www.minhajamaica.com/jamaica/historia/ 
Dub. A começar pelo Mento, conhecido como a origem de todos os ritmos famosos da Jamaica, percebe-se que é um estilo muito ligado a tradição folclórica do país, misturando o inglês com expressões indígenas e locais. A instrumentação característica conta com violão, flautas, metais e instrumentos simples de percussão. Seu ritmo é claramente derivado dos batuques africanos e em alguns momentos o canto se dá a capella. É possível perceber a influência deste ritmo no Blues americano.

O segundo ritmo jamaicano analisado é o Ska, que é marcante na Inglaterra, mas tem origem jamaicana. Este ritmo apresenta maior constância e maior velocidade também. Sua instrumentação conta com instrumentos de metais de forma muito nítida e, também, instrumentos mais modernos como a guitarra e o baixo elétrico. Sendo um ritmo protagonista dos bailes ingleses da década de 70 , suas letras falavam sobre a realidade dos bairros pobres da Inglaterra, a opressão da política, o trabalho e a condição de imigrante na Inglaterra.

Sua influência na cultura inglesa é tão marcante que em certo momento passou a ser tocado também por ingleses tradicionais que conviviam e habitavam os mesmos bairros dos imigrantes jamaicanos, sofrendo as mesmas dificuldades sociais, como desemprego e opressão da polícia. Além das músicas no estilo Ska, estes jovens ingleses, brancos, conhecidos como skinheads, usavam cabelos raspados e roupas escuras e influenciaram no surgimento do primeiro grande movimento cultural de periferia: o Punk.

É nesse momento que vemos a cultura jamaicana sendo apropriada pelos ingleses, incluída em sua cultura e espalhada para o mundo todo. Vale lembrar que nesta mesma década do surgimento do Punk, espalha-se a expressão rude boy, nos Estados Unidos chamados de bad boys, que fazia referência aos jovens que pertenciam a gangues de rua, adeptos das culturas de periferia. Esse termo já era usado na Jamaica e foi realocado para a Inglaterra, tido depois como símbolo das músicas dos Jamaicanos, um grito de identidade e talvez até de resistência e orgulho.

Já o Reggae é um ritmo mais conhecido e mais relacionado ao povo Jamaicano, e é, talvez, resultado de todos os ritmos já citados. Surgiu na década de 60 na Jamaica e é adotado pelos músicos de Ska, já bem conhecidos na Inglaterra. Na década de 70, o ritmo ganhou mais forma e representantes internacionais, agregando a questão da cultura Rastafari. Sua instrumentação conta com riffs de guitarra bem evidentes e linha baixo marcante. Em velocidade mais lenta que o Ska, o Reggae soa menos agressivo em pressão sonora.

$\mathrm{Na}$ estrutura das letras, inicialmente o Reggae abordava temáticas sobre relacionamentos amorosos, mas à medida que cresceu começou a abordar questões religiosas (Rastafári ou louvores a jah, referência a Deus), sociais e políticas. Este ritmo passou a carregar influências da música caribenha e do $R \& B$ americano, já não apresentando tantas expressões originais da Jamaica. Além do movimento inglês 2tone reggae, que mistura músicos brancos e negros música, muitas bandas nos mais diversos países inserem o Reggae em suas músicas.

O último estilo musical nativo da Jamaica analisado é o Dub, que surge também na década de 1960 na Jamaica. Este ritmo nasce apenas como um tipo de remix do Reggae e do Ska (além do Rock Steady, uma adaptação do rock para a Jamaica). A sonoridade conta com timbres de sintetizadores e distorções, além do eco e do destaque dado ao grave. Um desdobramento do Dub foi o Rap, mundialmente conhecido.

\section{DISCUSSÃO}

A partir disto, então, foram selecionadas e analisadas quatro músicas internacionais, entre norte-americanas e inglesas, a fim de identificar os elementos musicais que teriam origem na música jamaicana.

A primeira música analisada é Sympath for the Devil, da banda inglesa Rolling Stones. Original de Londres, a banda foi atuante no mesmo período da imigração jamaicana e acompanhou o contexto Ska/Reggae no Reino Unido. A música pertence ao álbum Beggars 
Banquet (Rolling Stones, 1968), e faz referências ao Mento jamaicano. Em sua estrutura musical apresenta um ritmo constante, evidenciada com batidas de tambor, caixa de Rhumba e chocalho que são instrumento marcante no Mento, riffs repetidos por piano, e contracantos e fundo harmônico feito por coral. No desenvolvimento da canção são apresentados os elementos do Rock, com solos de guitarra e melodias agudas, mas a constância dos instrumentos percussivos, não comum ao estilo Rock, é um destaque durante toda a música.

A segunda canção é a Man Down da cantora Rihanna. Nascida em Barbados, localizado na América Central, a cantora tem atuação profissional norte-americana. A canção foi lançada em 2010 no álbum Loud (Rihanna, 2010) e tem o ritmo característico do Ska/Reggae. Não conta com os metais marcantes do Ska, mas a linha de baixo, o órgão e os riffs estão muito presentes, sendo acrescentados também timbres sintetizados. Além disso, a música traz sons de sirene e tiros, comumente usados nas músicas do estilo Dub. A canção trata de assunto recorrente neste estilo, como analisado anteriormente, que é a questão do crime, realidade vivida nas periferias. Por conta de sua origem caribenha a música de Rihanna traz várias características da cultura jamaicana, a começar pelo sotaque, elemento notável da música jamaicana, bem como a repetição de palavras e o uso de vocabulário nativo.

A banda Maroon 5, que surgiu em Los Angeles na Califórnia, e lançou em 2012 a música One More Night do álbum Overexposed (Marron 5, 2012). Esta é uma canção de temática romântica, em ritmo de Reggae. A apropriação do estilo jamaicano é assumida ela banda norteamericana, mas também inclui elementos da música Pop, como a bateria eletrônica, por exemplo, e a sonoridade grave acentuada. Além disso, a Califórnia foi um dos estados que recebeu muitos imigrantes jamaicanos e, também, foi local de origem de muitas bandas Punk, influenciadas pelas bandas Punk inglesas, que, como discutido anteriormente, tiveram forte influência jamaicana.

A última canção analisada é LOVE. ft. Zacari, do álbum DAMN (Kendrick Lamar, 2017). Gravado pelo rapper Kendrick Lamar, este é tido como o melhor álbum de Rap dos últimos anos. Em uma primeira análise entende-se que todo Rap tem influência jamaicana, pois o primeiro $D J$ rapper foi Kool Herc foi jamaicano e usava do Dub em suas músicas nos bailes do Bronx. Desta forma, percebem-se alguns elementos musicais como o uso excessivo de sons de eletrônicos com efeitos processados de eco (delay e reverb), a ênfase dada ao grave e, repetições de frase estão presentes nesta música, e também comumente presente em outras músicas do estilo Rap.

\section{CONCLUSÃO}

As migrações jamaicanas para os países que possuíam grande protagonismo na indústria fonográfica e a língua como sendo um elemento de semelhança e proximidade influenciaram os cenários musicais das culturas dominantes, bem como em estilos e movimentos. Para Raibaud (2008, p. 2, tradução nossa) "[...] a música aparece como uma realidade cognitiva possível para compreender o espaço das sociedades, inclusive como um principio de organização territorial". Percebe-se tal influência não apenas em grupos musicais formados por artistas de origem caribenha, mas também por nativos europeus e norte-americanos que se apropriaram da cultura dos imigrantes.

Diante de tal situação também é legítimo observar a questão da resistência cultural que é levantada pelo povo jamaicano, nativos de uma ilha do terceiro mundo que sempre foi colônia e serviu aos países ricos do Norte, como Estados Unidos e Reino Unido. Causando certo impacto cultural às rádios desses países e de todo mundo, a música jamaicana é, também, resultado de uma mistura da cultura ameríndia e africana e se faz presente até hoje em várias partes do mundo. Assim, a música "borra" os mapas e tem o potencial de ampliar a compreensão de território e de lugar de escuta de cada povo. 


\section{REFERÊNCIAS}

KENDRICK LAMAR. Damn. Santa Mônica: Aftermath Entertainment, 2017. 1CD (54 min)

MAROON 5. Overexposed. Los Angeles: A\&M/Octone Records, 2012. 1CD (42 min)

RAIBAUD, Y. Comment la musique vient aux territoires. Bourdeaux: MSHA, 2008.

RIBEIRO, G. L. Imobilização e dispersão da força de trabalho: considerações sobre os modos de expansão concentrada e difusa. Brasília: Departamento de Antropologia, Universidade de Brasília, 1994.

RIHANNA. Loud. New York: Def Jam Recordings, 2010. 1CD (45 min)

ROLLING STONES. Beggars Banquet. London: Decca Records, 1968. 1CD (41 min) 